\title{
Vibration spectroscopy of complex formation in aqueous solutions of isopropanol
}

\author{
Kutsyk, A. M.; Ilchenko, O. O.; Yuzvenko, Ya M.; Obukhovsky, V. V.; Nikonova, V. V.
}

Published in:

Ukrainian Journal of Physics

Link to article, DOI:

10.15407/ujpe63.6.506

Publication date:

2018

Document Version

Publisher's PDF, also known as Version of record

Link back to DTU Orbit

Citation $(A P A)$ :

Kutsyk, A. M., Ilchenko, O. O., Yuzvenko, Y. M., Obukhovsky, V. V., \& Nikonova, V. V. (2018). Vibration spectroscopy of complex formation in aqueous solutions of isopropanol. Ukrainian Journal of Physics, 63(6), 506-512. https://doi.org/10.15407/ujpe63.6.506

\section{General rights}

Copyright and moral rights for the publications made accessible in the public portal are retained by the authors and/or other copyright owners and it is a condition of accessing publications that users recognise and abide by the legal requirements associated with these rights.

- Users may download and print one copy of any publication from the public portal for the purpose of private study or research.

- You may not further distribute the material or use it for any profit-making activity or commercial gain

- You may freely distribute the URL identifying the publication in the public portal 


\title{
PHYSICS OF LIQUIDS AND LIQUID \\ SYSTEMS, BIOPHYSICS AND MEDICAL PHYSICS
}

https://doi.org/10.15407/ujpe63.6.506

A.M. KUTSYK, ${ }^{1}$ O.O. ILCHENKO, ${ }^{2}$ YA.M. YUZVENKO,${ }^{1}$ V.V. OBUKHOVSKY,${ }^{1}$ V.V. NIKONOVA ${ }^{1}$

${ }^{1}$ Faculty of Radio Physics, Electronics and Computer Systems,

Taras Shevchenko National University of Kyiv

(4g, Acad. Glushkov Ave., Kyiv 03127, Ukraine; e-mail: a.m.kutsyk@gmail.com)

2 Department of Micro \& Nanotechnology, Technical University of Denmark

(345B, Ørsteds Plads, Lyngby 2800, Denmark)

\section{VIBRATION SPECTROSCOPY OF COMPLEX FORMATION IN AQUEOUS SOLUTIONS OF ISOPROPANOL}

\begin{abstract}
The formation of molecular complexes in isopropanol-water solutions is studied by means of vibrational spectroscopy techniques. The ATR FTIR spectra of solutions with different mixing ratios are detected. The multivariate curve resolution of the experimental data set shows that the investigated solution could be treated as a four-component mixture, which contains pure isopropanol, pure water, and two molecular complexes.

Ke ywords: complex formation, ATR FTIR spectroscopy, 2D correlation spectroscopy, multivariate curve resolution.
\end{abstract}

\section{Introduction}

Aqueous solutions of alcohols have been investigated for a long time, but the details of their molecular structure has not yet been realized completely [124 ]. Such great interest in water-alcohol solutions is caused due to their widespread usage in many areas, including chemical engineering and bioscience. In biochemical applications, alcohols are used as model species for complex amphiphilic molecules (e.g., proteins) $[25,26]$.

The physicochemical properties of alcohol-water solutions show an anomalous behavior in the whole concentration range. This means that their concentration dependence deviates greatly from the ideal behavior, for example, such properties of a solution as viscosity $[15,16]$, density [16], mutual and self-

(C) A.M. KUTSYK, O.O. ILCHENKO, YA.M. YUZVENKO, V.V. OBUKHOVSKY, V.V. NIKONOVA, 2018 diffusion coefficients [5, 20-23, 27, 28], excess thermodynamic functions $[10,14,15,29]$, dielectric permittivity $[4,8,9]$, refractive index [19], etc. Such nonlinear behavior is a macroscopic manifestation of a complex molecular structure of alcohol-water solutions. It was reported that alcohols-water solutions have inhomogeneous microstructure, i.e. alcohol and water do not mix completely at the molecular level [24]. Due to the hydrogen bond formation, both alcohol [30-32,51,52] and water $[33-36,53]$ tend to form self-associates. In addition, alcohol and water can form molecular complexes or heteroassociates $[1,10,13,18,37]$.

Vibrational (Raman and/or infrared) spectroscopy is a powerful tool for the investigation of the molecular structure of liquid solutions. Vibrational spectra are highly sensitive to structural changes in liquid solutions, which occur upon the mixing [3840]. The formation of complexes is accompanied by a change of some vibrational degrees of freedom,

ISSN 2071-0194. Ukr. J. Phys. 2018. Vol. 63, No. 6 
thus it causes the appearance of new intermolecular vibrations and/or a shift of intramolecular vibrations frequencies. The combination of vibrational spectroscopy with modern analytical techniques (such as a multivariate curve resolution, MCR [41]) could provide not only qualitative, but quantitative information (concentration of solution species) about the investigated system.

The aim of our research is the investigation of isopropanol-water solutions by means of vibrational spectroscopy. We continue our investigations of aqueous solutions of methanol series alcohols [27, 42]. At the moment, the study of the micro-heterogeneity in isopropanol-water solutions by NIR spectroscopy was presented in [18]. We are interested in the investigation of infrared spectra of the solutions in the range of $\mathrm{OH}$ stretching vibrations of isopropanol and water. This spectral region provides indirect information about the possible formation of $\mathrm{HO} \cdots \mathrm{H}$ hydrogen bonds, which are responsible for the self-association and complex formation (hetero-association) in isopropanol-water solutions.

\section{Materials and Methods}

\subsection{Samples and instrumentation}

Isopropanol and water with a purity of $99.9 \%$ were used in this research. ATR FTIR spectra were detected for solutions with different concentrations of isopropanol and water: from pure isopropanol to pure water with a concentration step of $5 \%$ (vol.). The accuracy of the concentration obtained by the mixing of liquids with the use of a micropipette was better than $0.1 \%$ (vol.). Mixed samples were stored in glass vials. IR spectra of the investigated solutions were detected in $24 \mathrm{~h}$ after the mixing to avoid the influence of relaxation processes. The temperature of the samples was stabilized at $25^{\circ} \mathrm{C}$. Infrared reflection spectra were registered, by using a FTIR spectrometer Thermo Fisher Scientific Nicolet iS50. All spectra were measured with a spectral resolution of $4 \mathrm{~cm}^{-1}$. The number of scans for each spectrum was 32. The more detailed description of spectroscopic measurements can be found in work [43].

\subsection{Analysis of residual spectra}

The analysis of residual spectra is used to enhance spectral deviations from the ideal solution behavior $[44,45]$. The idea of this method is quite straightfor- ward. If the investigated solution is ideal, its spectrum (Raman intensity or infrared absorbance) is a linear combination of pure spectral components. By the elimination of the ideal solution spectrum from the measured one, we obtain the residual spectrum:

$S_{\text {res }}\left(\nu, c_{1}, c_{2}\right)=S_{\text {meas }}\left(\nu, c_{1}, c_{2}\right)-S_{\text {ideal }}\left(\nu, c_{1}, c_{2}\right)=$

$=S_{\text {meas }}\left(\nu, c_{1}, c_{2}\right)-\left(c_{1} S_{1}(\nu)+c_{2} S_{2}(\nu)\right)$.

Here, $c_{1}$ and $c_{2}$ are the concentrations of component 1 and 2 , respectively.

The usage of the residual spectra (1) set at different concentrations can provide information about spectral regions, which are the most sensitive to the influence of intermolecular interactions. The method is proved to be useful to study the formation complexes in binary solutions [44-47].

\subsection{Multivariate curve resolution}

The multivariate curve resolution is a wide-spread chemometrics technique, which is used in spectroscopy for the determination of quantitative information about the investigated system. The goal of MCR methods is the estimation of the unknown contributions of different components in their mixtures (mixture analysis) [41]. It is supposed that the contribution of each component to the full spectrum is proportional to its pure spectrum. Thus, we use the bilinear form

$\mathbf{D}=\mathbf{C S}^{T}+\mathbf{E}$,

where $\mathbf{D}$ is the spectral data matrix, $\mathbf{C}$ represents the matrix of concentration profiles of the mixture components, the matrix $\mathbf{S}$ contains spectral profiles of the mixture components, and $\mathbf{E}$ represents the matrix of residuals. Equation (2) is solved by the multivariate curve resolution, by using the alternating least squares (MCR-ALS) method. The prior information about the investigated system is usually implemented as an additional constraint in the optimization problem. The ALS optimization under constraints helps us to avoid nonphysical solutions. The main drawback of the MCR-ALS decomposition is the ambiguity of the obtained solutions.

\subsection{Computation details}

The multivariate curve resolution is performed by Tauler's algorithm realized in MATLAB [48]. We applied the following constraints: nonnegativity, closure 




Fig. 1. ATR FTIR spectra of isopropanol-water solutions at different concentrations

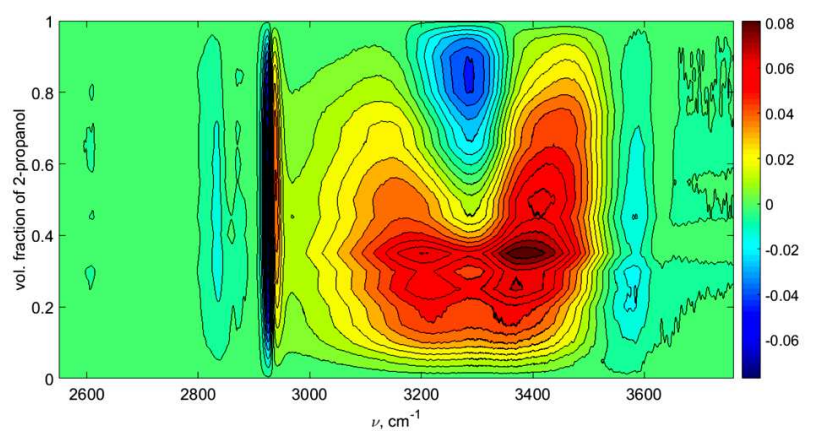

Fig. 2. ATR FTIR residual spectra

for concentration profiles, and nonnegativity for spectral profiles. Since we measured the pure spectra of isopropanol and water, we also fixed the spectra of pure components and their concentrations at the ends of the concentration region. As the initial estimation of profiles, which is needed for the starting of the iteration process of alternating least squares, the pure spectral variables were used; they were obtained, by the use of SIMPLISMA [49]. The constrained nonlinear optimization technique (MCR-BANDS [48]) was used for the detection of the ambiguity of MCR-ALS solutions.

\section{Results and Discussion}

\subsection{Residual spectra}

The spectral regions of $\mathrm{C}-\mathrm{H}$ stretching vibrations of isopropanol and $\mathrm{O}-\mathrm{H}$ stretching vibrations of isopropanol and water were chosen for the analysis due to their high sensitivity to the possible formation of a hydrogen bond. The corresponding measured ATR FTIR spectra are shown in Fig. 1.

The residual spectra were calculated by Eq. (1). The volume fractions of pure components before the mixing were used as concentration units. The difference between the usage volume and the molar fraction for the calculation of residual spectra is discussed in [47]. The residual spectral contour map is shown in Fig. 2. It can be seen that the residual distribution is not random; it shows a pronounced dependence on the concentration of a solution.

The ATR FTIR residual spectra map is characterized by the presence of two main maxima with positive values of the residues in the vicinities of $3200 \mathrm{~cm}^{-1}$ and $3440 \mathrm{~cm}^{-1}$. Their maximal values are reached at $35 \%$ (vol.) of isopropanol. In addition, the nonzero values of residuals are presented in the spectral region of $\mathrm{CH}$ stretching vibrations of isopropanol. It is an indirect evidence of that isopropanol can exist in different forms in the solution: as a part of a molecular complex and in the unbonded state.

\subsection{MCR-ALS decomposition}

To obtain the number of components presented in the solutions, we performed the principal component analysis (PCA) [50] of the experimental data matrix. Figure 3 shows the loadings of the first nine principal components (PC). We can see that the major contribution to the measured integral signal is made by the first four principal components. Hence, we performed the four-component MCR-ALS decomposition of the ATR FTIR spectra data matrix. The lack of a fit of the MCR-ALS decomposition equals lof = $=0.44 \%$. The MCR-BANDS optimization was performed to find the band boundaries of feasible spectral and concentration profiles. The obtained spectral and concentration profiles are shown in Figs. 4 and 5 . As we can see from Fig. 5, the obtained concentration profiles are not unique due to the presence of a rotation ambiguity. The latter is caused due to a high degree of the overlapping of both isopropanol and water spectra. The shaded areas at Fig. 5 show the feasible MCR-ALS solutions.

The obtained four components were identified, respectively, as "pure" isopropanol, "pure" water, complex 1, and complex 2. The maximal concentration of complex 1 is reached at $55 \%$ (vol.) of isopropanol. This corresponds to the isopropanol/water molar ratio equal to $1: 3.5$. We concerned this complex 




Fig. 3. Principal component loadings obtained from the ATR FTIR data matrix

as water-poor. The intensity of the $\mathrm{OH}$ band of the spectral profile of complex 1 is lower than the corresponding one in the spectral profile of complex 2. This supports our statement that complex 1 has a small amount of water molecules. The maximal concentration of complex 1 is about $30 \%$ (vol.). Complex 2 is the dominant structural unit in the water-rich region. The maximal concentration of complex 2 is reached at about of $30 \%$ (vol.) of isopropanol. The correspondent molar ratio of isopropanol to water equals $1: 8.8$. As this complex dominates at low concentrations of isopropanol, it has a small amount of isopropanol molecules. Thus, this can explain a small intensity of the $\mathrm{CH}$ band in its spectral profile.

As we can see from Fig. 4, the spectrum of complex 1 has a peak at about $3670 \mathrm{~cm}^{-1}$. This peak may be ISSN 2071-0194. Ukr. J. Phys. 2018. Vol. 63, No. 6



Fig. 4. ATR FTIR absorbance spectra of mixture components obtained by the MCR decomposition 
molar fraction of isopropanol, \%

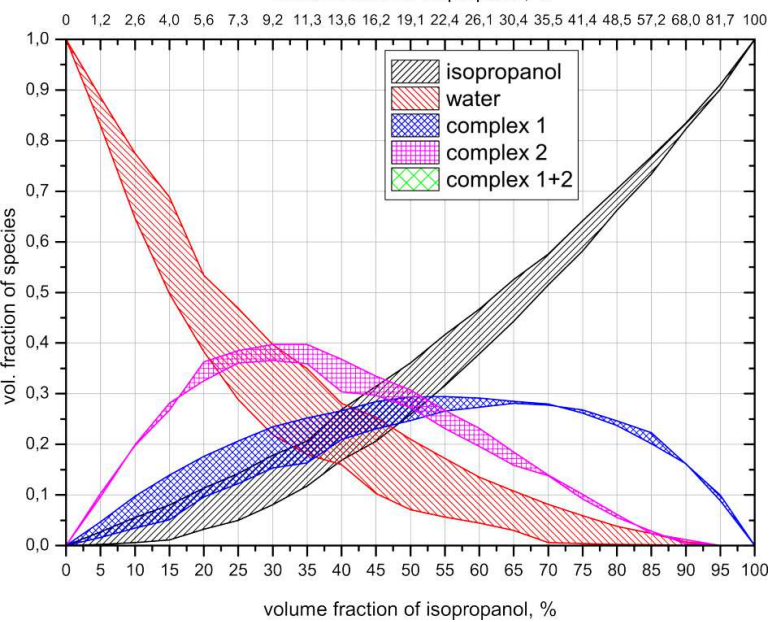

Fig. 5. Concentration profiles of solution components (dashed areas correspond to feasible solutions)

assigned to stretching vibrations of free $\mathrm{OH}$ groups of isopropanol or water. The absence of such peak in the spectral profiles of the "pure" component and complex 1 means that they are formed of dominated cyclic entities. It is worth to note that the obtained spectra of "pure" components are practically identical to the corresponding ones of the bulk state (see Figs. 1 and 4). This means that the associates of isopropanol and water in solutions are close to those in bulk isopropanol and water.

We note that the regions, where the concentration of complexes is dominant, correspond to concentration regions, where some physical characteristics of solutions have extreme values $[3,4,6-8]$. The domination of complex 2 in the water-rich region could explain the following features of isopropanol-water solutions: minimal value of the self-diffusion coefficient of isopropanol [4], minimal value of the mutual diffusion coefficient [20], maximal value of the dielectric permittivity [4], maximal value of the terahertz absorption coefficients [3], maximal value of the sound absorption coefficient [7], and minimal value of the negative excess enthalpy $[3,6]$. The presence of two types of complexes could explain the existence of a minimum and a maximum of the concentration dependence of the excess enthalpy $[3,6]$.

\section{Conclusion}

The ATR FTIR spectra of isopropanol-water solutions have been studied in the whole concentration range. The formation of complexes in the investigated solutions causes a nonlinear dependence of the intensities of spectra on the concentration, which was detected by the analysis of residual spectra.

The MCR-ALS decomposition of the spectral data matrix is performed. The experimental results confirm the possibility to describe the structure of a liquid isopropanol-water solution (from the spectroscopic point of view) as a combination of four components: "pure" isopropanol, "pure" water, and complexes consisting of both types of molecules, waterrich and water-poor. The correct determination of the stoichiometry of complexes needs additional investigations. For example, it may be estimated by the usage of a model-based multivariate decomposition of vibrational spectra [46]. Additional information may be obtained by ab initio quantum chemical calculations.

The formation of molecular complexes can explain the anomalous concentration dependence of the physicochemical properties of isopropanol-water solutions. The presence of extreme points in the concentration dependences may be related to the domination of molecular complexes in the corresponding concentration region.

1. M.K. Alam, J.B. Callis. Elucidation of species in alcoholwater mixtures using near-IR spectroscopy and multivariate statistics, Anal. Chem. 66, 2293 (1994).

2. K. Yoshida, T. Yamaguchi. Low-frequency Raman spectroscopy of aqueous solutions of aliphatic alcohols. $\mathrm{Z}$. $\mathrm{Na}$ turforsch. 56a, 529 (2001).

3. J. McGregor, R. Li, J. Axel Zeitler, C. D'Agostino, J.H.P. Collins, M.D. Mantle, H. Mayar, J.D. Holbrey, M. Falkowska, T.G.A. Youngs, C. Hardacre, E. Hugh Stitt, L.F. Gladden. Structure and dynamics of aqueous 2-propanol: a THz-TDS, NMR and neutron diffraction study. Phys. Chem. Chem. Phys. 17, 30481 (2015).

4. R. Li, C. D'Agostino, J. McGregor, M.D. Mantle, A. Zeitler, L.F. Gladden. Mesoscopic structuring and dynamics of alcohol/water solutions probed by terahertz time-domain spectroscopy and pulsed field gradient nuclear magnetic resonance. J. Phys. Chem. B 118, 10156 (2014).

5. H.-J. Tong, J.-Y. Yu, Y.-H. Zhang, J.P. Reid. Observation of conformation changes in 1-propanol-water complexes by FTIR spectroscopy. J. Phys. Chem. A 114, 6795 (2010).

6. J.W. Bye, C.L. Freeman, J.D. Howard, G. Herz, J. McGregor, R.J. Falconer. Analysis of mesoscopic structured 2-propanol/water mixtures using pressure perturbation calorimetry and molecular dynamic simulation. J. Solut. Chem. 46, 175 (2017).

7. L.A. Bulavin, A.V. Chalyi, O.I. Bilous. Anomalous propagation and scattering of sound in 2-propanol water solution near its singular point. J. Mol. Liq.. 235, 24 (2017).

ISSN 2071-0194. Ukr. J. Phys. 2018. Vol. 63, No. 6 
8. T. Sato, R. Buchner. Dielectric relaxation spectroscopy of 2-propanol-water mixtures. J. Chem. Phys. 118, 4606 (2003).

9. T. Sato, R. Buchner. The cooperative dynamics of the H-bond system in 2-propanol/water mixtures: Steric hindrance effects of nonpolar head group. J. Chem. Phys. 119, 10789 (2003).

10. D. Peeters, P. Huyskens. Endothermicity of water/alcohol mixtures. J. Mol. Struct. 300, 539 (1993).

11. L.A. Bulavin, V.Ya. Gotsulskii, N.P. Malomuzh, V.E. Chechko. Relaxation and equilibrium properties of dilute aqueous solutions of alcohols. Russ. Chem. Bull. 65, 851 (2016).

12. J.-H. Guo, Y. Luo, A. Augustsson, S. Kashtanov, J.-E. Rubensson, D.K. Shuh, H. Ågren, J. Nordren. Molecular structure of alcohol-water mixtures. Phys. Rev. Lett. 91, 157401 (2003)

13. T.A. Dolenko, S.A. Burikov, S.A. Dolenko, A.O. Efitorov, I.V. Plastinin, V.I. Yuzhakov, S.V. Patsaeva. Raman Spectroscopy of Water-Ethanol Solutions: The Estimation of Hydrogen Bonding Energy and the Appearance of Clathrate-like Structures in Solutions. J. Phys. Chem. A, 119, 10806 (2015).

14. V.Ya. Gotsul'skii, N.P. Malomuzh, V.E. Chechko. Features of the temperature and concentration dependences of the contraction of aqueous solutions of ethanol. Russ. J. Phys. Chem. A 87, 1638 (2013).

15. H. Yilmaz. Excess properties of alcohol-water systems at 298.15 K. Turk. J. Phys. 26, 243 (2002)

16. F.-M. Pang, C.-E. Seng, T.-T. Teng, M.H. Ibrahim. Densities and viscosities of aqueous solutions of 1-propanol and 2-propanol at temperatures from $293.15 \mathrm{~K}$ to $333.15 \mathrm{~K}$. J. Mol. Liq. 136, 71 (2007).

17. A.Yu. Manakov, L.S. Aladko, A.G. Ogienko, A.I. Ancharov. Hydrate formation in the system of n-propanolwater. J. Therm. Anal. Calorim.. 111, 885 (2013).

18. P. Tomza, M.A. Czarnecki. Microheterogeneity in binary mixtures of propyl alcohols with water: NIR spectroscopic, two-dimensional correlation and multivariate curve resolution study. J. Mol. Liq. 209, 115 (2015).

19. L.A. Bulavin, V.Ya. Gotsul'skii, N.P. Malomuzh, M.V. Stiranets. Refractometry of water-ethanol solutions near their contraction point. Ukr. J. Phys. 60, 1108 (2015).

20. K.C. Pratt, W.A. Wakeham. The mutual diffusion coefficient for binary mixtures of wster and the isomers of propanol. Proc. R. Soc. Lond. A. 342, 401 (1975).

21. K.R. Harris, T. Goscinska, H.N. Lam. Mutual diffusion coefficients for the systems water-ethanol and water-propan1-ol at $25{ }^{\circ}$ C. J. Chem. Soc. Faraday Trans. 89, 1969 (1993).

22. A. Mialdun, V. Yasnou, V. Shevtsova, A. Königer, W. Köhler, D. Alonso de Mezquia, M. M. Bou-Ali. A comprehensive study of diffusion, thermodiffusion, and Soret coefficients of waterisopropanol mixtures. J. Chem. Phys. 136, 244512 (2012)

ISSN 2071-0194. Ukr. J. Phys. 2018. Vol. 63, No. 6
23. L. Hao, D.G. Leaist. Binary mutual diffusion coefficients of aqueous alcohols. Methanol to 1-heptanol. J. Chem. Eng. Data 41, 210 (1996).

24. S. Dixit, J. Crain, W.C.K. Poon, J.L. Finney, A.K. Soper. Molecular segregation observed in a concentrated alcoholwater solution. Nature 416, 829 (2002).

25. J.G. Davis, K.P. Gierszal, P. Wang, D. Ben-Amotz. Water structural transformation at molecular hydrophobic interfaces. Nature 491, 582 (2012).

26. J.G. Davis, B.M. Rankin, K.P. Gierszal, D. Ben-Amotz. On the cooperativity of non-hydrogen-bonded water at molecular hydrophobic interfaces. Nature Chem. 5, 796 (2013).

27. V.V. Obukhovsky, V.V. Nikonova. Interdiffusion in water solutions of ethyl alcohol. Ukr. J. Phys. 55, 891 (2010).

28. K.V. Cherevko, D.A. Gavryushenko, V.M. Sysoev. Stationary diffusion in the membrane systems with the ongoing reversible chemical reactions. J. Mol. Liq. 120, 71 (2005).

29. H.A. Zarei, S. Shahvarpour. Volumetric properties of binary and ternary liquid mixtures of 1-propanol $(1)+2$ propanol (2) + water (3) at different temperatures and ambient pressure (81.5 kPa). J. Chem. Eng. Data 53, 1660 (2008).

30. J.-W. Shin, E.R. Bernstein. Experimental and theoretical studies of isolated neutral and ionic 2-propanol and their clusters. J. Chem. Phys. 130, 214306 (2009).

31. I.Yu. Doroshenko. Matrix isolation study of the formation of methanol cluster structures in the spectral region of $\mathrm{C}$ $\mathrm{O}$ and O-H stretch vibrations. Low Temp. Phys. 37, 604 (2011).

32. G. Matisz, A.-M. Kelterer, W.M.F. Fabian, S. KunságiMáté. Application of the quantum cluster equilibrium (QCE) model for the liquid phase of primary alcohols using B3LYP and B3LYP-D DFT methods. J. Phys. Chem. $B$ 115, 3936 (2011).

33. M. Starzak, M. Mathlouthi. Cluster composition of liquid water derived from laser-Raman spectra and molecular simulation data. Food Chem. 82, 3 (2003).

34. H. Cybulski, J. Sadlej. On the calculation of the vibrational Raman spectra of small water clusters. Chem. Phys. 342, 163 (2007).

35. S.R. Gadre, S.D. Yeole, N. Sahu. Quantum cluster investigations of molecular clusters. Chem. Rev. 114, 12132 (2014).

36. F. Weinhold. Quantum cluster equilibrium theory of liquids: Illustrative applications to water. J. Chem. Phys. 109, 373 (1998).

37. G. Matisz, A.-M. Kelterer, W.M.F. Fabian, S. KunságiMáté. Structural properties of methanol-water binary mixtures within the quantum cluster equilibrium model. Phys. Chem. Chem. Phys. 17, 8467 (2015).

38. H.F. Shurvel. Spectra-structure correlations in the midand far-infrared. In Handbook of Vibrational Spectroscopy. Edited by J.M. Chalmers, P.R. Griffiths (Wiley, 2002). 
39. L.G. Weyer, S.-C. Lo. Spectra-structure correlations in the near-infrared. In Handbook of Vibrational Spectroscopy. Edited by J.M. Chalmers, P.R. Griffiths (Wiley, 2002).

40. H.G.M. Edwards. Spectra-structure correlations in Raman spectroscopy. In Handbook of Vibrational Spectroscopy. Edited by J.M. Chalmers, P.R. Griffiths (Wiley, 2002).

41. A. de Juan, R. Tauler. Multivariate curve resolutionalternating least squares for spectroscopic data. In $R e$ solving Spectral Mixtures with Applications from Ultrafast Time-Resolved Spectroscopy to Super-Resolution Imaging (Elsevier, 2016)

42. O. Ilchenko, V. Obukhovsky, V. Lemeshko, V. Nikonova, A. Kutsyk. Raman spectroscopy investigations of complexation processes in water-methanol solutions. Bulletin of T. Shevchenko Nat. Univ. of Kyiv. Radiophys. Electr. 17, 34 (2012).

43. O.O. Ilchenko, Y.V. Pilgun, A.S. Reynt, A.M. Kutsyk. NNLS and MCR-ALS decomposition of Raman and FTIR spectra of multicomponent liquid solutions. Ukr. J. Phys. 61, 519 (2016).

44. Q. Li, N. Wang, Q. Zhou, S. Sun, Z. Yu. Excess infrared absorption spectroscopy and its applications in the studies of hydrogen bonds in alcohol-containing binary mixtures. Appl. Spec. 62, 166 (2008).

45. O. Ilchehko, V. Nikonova, A. Kutsyk, V. Obukhovsky. Quantitative analysis of complex formation in acetonechloroform and ethyl acetate-cyclohexane solutions. $U k r$. J. Phys. 59, 268 (2014).

46. O.O. Ilchenko, A.M. Kutsyk, Y.V. Pilgun, V.V. Obukhovsky, V.V. Nikonova. Formation of molecular complexes in liquid benzene-chloroform mixtures examined by mid-IR $2 \mathrm{D}$ correlation spectroscopy and multivariate curve resolution. Ukr. J. Phys. 61, 508 (2016).

47. A. Kutsyk, O. Ilchenko, Y. Pilgun, V. Obukhovsky, V. Nikonova. Complex formation in liquid diethyl etherchloroform mixtures examined by 2D correlation mid-IR spectroscopy. J. Mol. Struct. 1124, 117 (2016).
48. J. Jaumot, A. de Juan, R. Tauler. MCR-ALS GUI 2.0: New features and applications. Chem. Intell. Lab. Sys. 140, 1 (2015).

49. S. Kucheryavskiy, W. Windig, A. Bogomolov. Spectral unmixing using the concept of pure variables. In Resolving Spectral Mixtures with Applications from Ultrafast TimeResolved Spectroscopy to Super-Resolution Imaging (Elsevier, 2016).

50. K.H. Esbensen, P. Geladi. Principal component analysis: concept, geometrical interpretation, mathematical background, algorithms, history, practice. In Comprehensive Chemometrics (Elsevier, 2009).

51. I.Yu. Doroshenko. Spectroscopic study of the n-hexanol cluster structure, isolated in an argon matrix. Low Temp. Phys. 43, 732 (2017).

52. I. Doroshenko, V. Balevicius, G. Pitsevich, K. Aidas, V. Sablinskas, V. Pogorelov. FTIR/PCA study of propanol in argon matrix: The initial stage of clustering and conformational transitions. Low Temp. Phys. 40, 1077 (2014).

53. V.Ye. Pogorelov, I.Yu. Doroshenko, Vibrational spectra of water clusters, trapped in low temperature matrices. Low Temp. Phys. 42, 1163 (2016).

Received 03.12.17

А.М. Куцик, О.О. Ілъченко,

Я.М. Юзвенко, В.В. Обуховсъкий, В.В.Ніконова

КОЛИВАЛЬНА СПЕКТРОСКОПІЯ

КОМПЛЕКСОУТВОРЕННЯ У ВОДНИХ

РОЗЧИНАХ ІЗОПРОПАНОЛУ

$\mathrm{P}$ е $з$ ю м е

Було досліджено комплексоутворення у розчинах ізопропанолу з водою методами коливальної спектроскопії. ППВВ спектри IЧ поглинання в режимі було виміряно при різних концентраціях розчину. Багатовимірне розділення кривих експериментальних даних показало, що досліджуваний розчин можна розглядати як чотирикомпонентну суміш, що містить дві незв'язані компоненти ("чисту" воду та "чистий" ізопропанол) та два молекулярні комплекси. 